Original Article

\title{
Evaluation of Serum Neutrophil to Lymphocyte Ratio in the Results of Thyroid Fine Needle Aspiration; Can It Discriminate a Clinical Benefit for the Atypia of Undetermined Significance?
}

\author{
Ozlem OZDEMIR ${ }^{1}$ (D) Hamza CINAR $^{2}$ (D) , Cagri AKALIN $^{3}$ (D), Muruvvet AKCAY CELIK $^{4}$ (D) \\ ${ }^{1}$ Department of Internal Medicine, School of Medicine, Ordu University, Ordu, Turkey \\ ${ }^{2}$ Department of General Surgery, School of Medicine, Abant Izzet Baysal University, Bolu, Turkey \\ ${ }^{3}$ Department of General Surgery, School of Medicine, Ordu University, Ordu, Turkey \\ ${ }^{4}$ Department of Pathology, School of Medicine, Ordu University, Ordu, Turkey
}

\section{A B S T R A C T}

Background Thyroid biopsy results are evaluated according to The Bethesda System for reporting thyroid cytopathology worldwide. The most ambiguous result from these categories is the Bethesda-III which is defined as "atypia of undetermined significance" (AUS). Neutrophil to lymphocyte ratio (NLR) is still evaluated in thyroid disorders and malignancy. The purpose of this study was to evaluate the NLR results in Bethesda categories and whether the NLR can discriminate a clinical benefit for the AUS category.

Material and Methods In this retrospective study, 1771 patients who had fine needle aspiration biopsy were examined. Demographic characteristics, NLR, Bethesda scores, operation rates and postoperative histopathological results were recorded.

Results The categories were; Bethesda-I for 298 (16.8\%), Bethesda-II for 1320 (74.5\%), Bethesda-III for 60 (3.4\%), Bethesda-IV for 27 (1.5\%), Bethesda-V for $36(2 \%)$, Bethesda-VI for 30 (1.7\%) results respectively. The mean NLR was 2.68 . There was no statistically significant difference between groups in terms of NLR ( $p=0.250)$. Overall, $226(12.76 \%)$ patients were underwent thyroidectomy. The AUS group was found by $3.4 \%$, operation rate was $21.66 \%$ and malignancy rate was $23.07 \%$. There was a statistically significant difference between Bethesda scores and malignancy rates $(p<0.001)$. There was no statistically significant difference between the postoperative results in terms of NLR ( $p=0.973)$.

Conclusions The NLR does not differ according to the Bethesda categories neither the postoperative histopathological results. It is not a predictive parameter for the benign or malignant differentiation. We think that NLR cannot discriminate a clinical benefit for the surgery decision in the follow-up of the AUS category.

Turk J Int Med 2021;3(4):188-194

DOI: $10.46310 /$ tjim.898205

Keywords: Neutrophil to lymphocyte ratio, Bethesda categories, fine needle aspiration biopsy, atypia of undetermined significance, thyroid malignancy.

Address for Correspondence:
Ozlem Ozdemir,MD
Department of Internal Medicine, School of Medicine, Ordu University, Ordu, Turkey




\section{Introduction}

Thyroid nodule is a frequent problem in the clinical practice. While the detection rate of the nodule by the palpation is about $4 \%$ due to the inability to recognize the small ones, this rate is up to $68 \%$ by the thyroid ultrasonography (USG). ${ }^{1}$ Malignancy rate in thyroid nodule is about $5-10 \%$ that is why a careful examination is required. ${ }^{1}$ The gold standard diagnostic method for the thyroid nodule is fine-needle aspiration biopsy (FNAB) and cytopathologic evaluation. The Bethesda System for reporting thyroid cytopathology (TBSRTC) has been used increasingly since 2007 to classify thyroid nodules and this system broadly classifies thyroid nodules into six categories stratified by risk of malignancy. ${ }^{2}$ In these categories, atypia of undetermined significance (AUS) or follicular lesion of undetermined significance (FLUS) category is still the most ambiguous and it is not benign neither malignant.

This category introduce the suspicious, atypical cytological or architectural features, but do not diagnose follicular neoplasm (FN) or suspicious for a follicular neoplasm (SFN), suspicious for malignancy (SM) status.

Systemic inflammatory response was found to be related to cancer pathophysiology in recent years. ${ }^{3-5}$ Neutrophil to lymphocyte ratio (NLR) is an indicator of systemic inflammatory response and has been associated with the pathogenesis, development, progression, metastasis and even respond to treatment in solid tumors especially. ${ }^{6-8}$ Many studies evaluating NLR in terms of thyroid malignancy give dissimilar results. ${ }^{9-13}$ On the other hand, the value of NLR in the benign or malignant differentiation in the AUS category is not clear.

The aim of this study is to examine the FNAB results, to compare the Bethesda categories in terms of NLR, to evaluate the pathology results in patients who underwent thyroidectomy, and to see whether NLR is effective in the benignmalignant differentiation in the AUS category.

\section{Material and Methods}

\section{Study Design}

This study is a retrospective-cohort study. The results of the patients with thyroid nodule who were admitted to Education and Research Hospital of Medicine Faculty of University Ordu and Ordu State Hospital between May 2018 and December 2019 were evaluated. Demographic information and medical histories related to disease were obtained from patient files. This study was approved by the Ethics Committee of the Medicine Faculty of University Ordu (Number 2018-111).

\section{Patient Selection}

Patients older than 18 years old with thyroid nodule and normal thyroid function tests, without any diagnosed thyroid disease were included in the study. Any systemic disease, malignancy and drug use were also in exclusion criteria.

\section{Data Collection}

Age, gender, hemogram parameters, FNAB and postoperative histopathological results were analyzed.

\section{Laboratory and Pathological Parameters}

Hemogram parameters taken before FNAB were evaluated. White blood cell count (WBC), neutrophil count $(\mathrm{N})$, lymphocyte count $(\mathrm{L})$, were obtained from the complete blood count report. NLR was calculated as the neutrophil count divided by the lymphocyte count.

FNAB and post-surgery specimens were evaluated by the same pathologists in our hospital. According to TBSRTC, the results of FNAB were divided into six groups: I- Nondiagnostic (ND), II- Benign, III- AUS/FLUS, IV- FN/SFN, V- SM, and VI- Malignancy.

\section{Statistical Analysis}

Analysis of data used the Statistical Package for the Social Sciences 22 (SPSS, Inc, Chicago IL, USA). Continuous variables were expressed as descriptive statistics; mean, standard deviation, minimum and maximum values. Categorical variables were expressed as number and percentage. Mann-Whitney U test was used for continuous 
variables. Chi-square test was used to determine the relationship between categorical variables. $\mathrm{P}$ values of $<0.05$ were considered statistically.

\section{Results}

In this study, 1771 patients were analyzed. Mean age was $54.12 \pm 13$ years old. As 1,465 (82.72\%) of the patients were female, $306(17.28 \%)$ were males. The categories were; Bethesda-I for 298 (16.8\%), Bethesda-II for 1,320 (74.5\%), Bethesda-III for 60 (3.4\%), Bethesda-IV for 27 (1.5\%), Bethesda-V for $36(2 \%)$, Bethesda-VI for $30(1.7 \%)$ patients respectively. There was no difference in term of gender but a significantly statistical difference in term of age between the groups $(p=0.026)$. Descriptive parameters are given in Table 1 . The mean NLR value was 2.68 (0.59-16.80); 3.12 (0.6915.7) for males and $2.59(0.59-16.80)$ for females. The median value of NLR was found to be 2.11.

There was no statistically significant difference between Bethesda groups in terms of NLR $(p>0.05)$ (Table 2).

It was detected that $226(12.76 \%)$ patients were underwent thyroidectomy during the follow-up period.
These patients were $33(11.07 \%)$ of 298 in Bethesda-I, 87 (6.59\%) of 1,320 in Bethesda-II, 13 (21.66\%) of 60 in Bethesda-III, and all of the Bethesda-IV, Bethesda-V, Bethesda-VI groups. The postoperative histopathological results were found benign in 133 patients and malign in 93. No significant difference was found between the benign and malign results in terms of NLR. Postoperative histopathological results were given in Table 3 .

The malignancy rates in patients with thyroidectomy were $12.5 \%$ in Bethesda-I, $26.43 \%$ in Bethesda-II, $23.07 \%$ in Bethesda-III, $40.74 \%$ in Bethesda-IV, 61.1\% in Bethesda-V, and 93.3\% in Bethesda-VI groups. There was a statistically significant difference between Bethesda scores and malignancy rates $(\mathrm{p}<0.001)$. No statistically significant difference was found between the patients with thyroidectomy in Bethesda groups in terms of NLR (Table 4).

\section{Discussion}

In this study, 1,465 (82.7\%) of 1,771 patients with thyroid nodule were female and 306 (17.3\%) were males. According to TBSRTC, the results were in benign (Bethesda-II) category for 1,097 (74,93\%)

Table 1. Demographic characteristics of the groups

\begin{tabular}{|c|c|c|c|c|c|c|c|}
\hline Variables & $\begin{array}{c}\text { Bethesda-I } \\
(n=298)\end{array}$ & $\begin{array}{c}\text { Bethesda-II } \\
(n=1320)\end{array}$ & $\begin{array}{l}\text { Bethesda-III } \\
\quad(n=60)\end{array}$ & $\begin{array}{l}\text { Bethesda-IV } \\
\quad(n=27)\end{array}$ & $\begin{array}{c}\text { Bethesda-V } \\
\quad(n=36)\end{array}$ & $\begin{array}{l}\text { Bethesda-VI } \\
\quad(n=30)\end{array}$ & $P$ value \\
\hline $\begin{array}{l}\text { Age (meantsd) } \\
\quad \text { (range) }\end{array}$ & $\begin{array}{c}54.33 \pm 13.4 \\
(23-91)\end{array}$ & $\begin{array}{l}54.15 \pm 13.1 \\
\quad(21-95)\end{array}$ & $\begin{array}{c}56.32 \pm 14.0 \\
(27-86)\end{array}$ & $\begin{array}{c}52.70 \pm 17.2 \\
(24-84)\end{array}$ & $\begin{array}{c}55.78 \pm 14.9 \\
(16-88)\end{array}$ & $\begin{array}{c}45.97 \pm 14.9 \\
(15-77)\end{array}$ & 0.026 \\
\hline \multicolumn{8}{|l|}{ Gender } \\
\hline Female & 235 & 1098 & 49 & 25 & 33 & 25 & \\
\hline Male & 63 & 222 & 11 & 2 & 3 & 5 & 0.165 \\
\hline
\end{tabular}

sd: standart deviation, $\mathrm{p}<0.05$ is considered to be significant

Table 2. NLR values of the groups

\begin{tabular}{llllllll}
\hline Variables & $\begin{array}{l}\text { Bethesda-I } \\
(\mathrm{n}=298)\end{array}$ & $\begin{array}{l}\text { Bethesda-II } \\
(\mathrm{n}=1320)\end{array}$ & $\begin{array}{l}\text { Bethesda-III } \\
(\mathrm{n}=60)\end{array}$ & $\begin{array}{l}\text { Bethesda-IV } \\
(\mathrm{n}=27)\end{array}$ & $\begin{array}{l}\text { Bethesda-V } \\
(\mathrm{n}=36)\end{array}$ & $\begin{array}{l}\text { Bethesda-VI } \\
(\mathrm{n}=30)\end{array}$ & P value \\
\hline $\begin{array}{c}\text { NLR (mean } \pm \mathrm{sd}) \\
\text { (range) }\end{array}$ & $\begin{array}{l}2.69 \pm 1.70 \\
(0.67-11.9)\end{array}$ & $\begin{array}{c}2.71 \pm 1.78 \\
(0.59-16.8)\end{array}$ & $\begin{array}{c}2.47 \pm 1.78 \\
(0.74-9.14)\end{array}$ & $\begin{array}{r}2.28 \pm 0.91 \\
(1.17-4.40)\end{array}$ & $\begin{array}{r}2.29 \pm 1.61 \\
(0.70-8.90)\end{array}$ & $\begin{array}{c}2.80 \pm 1.63 \\
(0.72-6.70)\end{array}$ & 0.250 \\
\hline
\end{tabular}

sd: standart deviation, $\mathrm{p}<0.05$ is considered to be significant, NLR: Neutrophil to lymphocyte ratio 
Table 3. Postoperative histopathological results according to Bethesda Scores

\begin{tabular}{|c|c|c|c|c|c|c|c|}
\hline Pathology Results & $\begin{array}{l}\text { Bethesda-I } \\
(\mathrm{n}=33)\end{array}$ & $\begin{array}{l}\text { Bethesda-II } \\
(\mathrm{n}=87)\end{array}$ & $\begin{array}{l}\text { Bethesda-III } \\
\quad(\mathrm{n}=13)\end{array}$ & $\begin{array}{l}\text { I Bethesda-IV } \\
\quad(n=27)\end{array}$ & $\begin{array}{c}\text { Bethesda-V } \\
(\mathrm{n}=36)\end{array}$ & $\begin{array}{l}\text { Bethesda-VI } \\
\quad(n=30)\end{array}$ & $\begin{array}{c}\text { Total } \\
\mathrm{N}=226\end{array}$ \\
\hline \multicolumn{8}{|l|}{ Benign } \\
\hline Multinoduler goiter & 11 & 18 & 2 & 6 & 3 & - & 43 \\
\hline Colloidal nodule & 2 & 2 & 1 & 1 & 3 & - & 9 \\
\hline Nodular hyperplasia & 9 & 33 & 4 & 3 & 2 & - & 51 \\
\hline Follicular adenoma & 6 & 2 & 1 & 1 & 2 & 1 & 13 \\
\hline Hashimoto's thyroditis & - & 1 & - & 1 & 1 & - & 3 \\
\hline Lymphocytic thyroiditis & - & 4 & 1 & 1 & 1 & - & 7 \\
\hline Adenomatous hyperplasia & - & 3 & - & 1 & 1 & - & 5 \\
\hline Diffuse hyperplasia & - & - & - & 1 & 1 & - & 2 \\
\hline Granulomatous thyroiditis & - & 1 & - & 1 & - & 1 & 3 \\
\hline \multicolumn{8}{|l|}{ Malign } \\
\hline Papillary cancer & 4 & 20 & 2 & 7 & 16 & 24 & 70 \\
\hline Hurtle cell neoplasia & - & 1 & 1 & 2 & 4 & - & 8 \\
\hline Oncocytic cell nodule & 1 & 1 & 1 & 2 & 1 & - & 6 \\
\hline Mucoepidermoid carcinoma & - & - & - & - & 1 & 2 & 3 \\
\hline Medullary carcinoma & - & 1 & - & - & - & 2 & 3 \\
\hline Total & 33 & 87 & 13 & 27 & 36 & 30 & 226 \\
\hline
\end{tabular}

women and $222(72.07 \%)$ men. It is known that thyroid nodules are approximately 4 times more common and benign in women than men. ${ }^{1} \mathrm{We}$ found similar results in this study. Although the Bethesda-VI age was significantly lower than the other groups, it was compatible with the ages at which thyroid cancer was seen and was not in the primary aim of our study.

In this study, no significant difference was found between Bethesda groups in terms of NLR. Many studies of the NLR in the thyroid diseases are mostly on its evaluation in benign-malign differentiation and offers contrasting results. In the study of Kocer et al. ${ }^{9}$, NLR was significantly higher in the papillary thyroid cancer group than the multinodular goiters group. Similarly, Çadırc1 et al. ${ }^{10}$ reported a significant difference in NLR between the differentiated thyroid cancer and healthy groups. In another study, mean NLR of malign nodule group was significantly higher than both those in benign nodule that therefore it was suggested that elevated NLR may be an indicator of underlying malign nodular disease in preoperative period. ${ }^{11}$ In contrast, Yaylaci et al. ${ }^{12}$ reported that NLR was not different in patients with benign nodular goiter and papillary thyroid cancer. In a meta-analysis conducted by Liu et $a l .{ }^{13}$, it was concluded that the benign nodules and the differentiated thyroid cancers did not differ in terms of NLR.

In the Bethesda-VI category 30 results were detected but the malignant results increased to 93 cases according to the postoperative pathology results. Thus, malignancy rate was found to be $5.24 \%$ in this study. This rate is similar to the expected rate in the population as $5-10 \%$. Also, malignancy rates in patients with thyroidectomy were similar to those stated in TBSRTC only it 
Table 4. NLR values of those operated on according to Bethesda groups

\begin{tabular}{llllllll}
\hline Variables & $\begin{array}{l}\text { Bethesda-I } \\
(\mathrm{n}=33)\end{array}$ & $\begin{array}{l}\text { Bethesda-II } \\
(\mathrm{n}=87)\end{array}$ & $\begin{array}{l}\text { Bethesda-III } \\
(\mathrm{n}=13)\end{array}$ & $\begin{array}{l}\text { Bethesda-IV } \\
(\mathrm{n}=27)\end{array}$ & $\begin{array}{l}\text { Bethesda-V } \\
(\mathrm{n}=36)\end{array}$ & $\begin{array}{l}\text { Bethesda-VI } \\
(\mathrm{n}=30)\end{array}$ & P value \\
\hline $\begin{array}{c}\text { NLR (mean } \pm \mathrm{sd}) \\
\text { (range) }\end{array}$ & $\begin{array}{l}2.61 \pm 1.75 \\
(0.70-7.65)\end{array}$ & $\begin{array}{l}2.553 \pm 1.40 \\
(0.84-8.91)\end{array}$ & $\begin{array}{r}2.49 \pm 1.20 \\
(1.12-5.30)\end{array}$ & $\begin{array}{r}2.29 \pm 0.97 \\
(1.19-4.40)\end{array}$ & $\begin{array}{r}2.58 \pm 1.25 \\
(1.38-5.60)\end{array}$ & $\begin{array}{r}2.91 \pm 1.76 \\
(0.72-6.70)\end{array}$ & 0.973 \\
\hline
\end{tabular}

sd: standart deviation, $\mathrm{p}<0.05$ is considered to be significant, NLR: Neutrophil to lymphocyte ratio

was found to be higher in the group Bethesda-II $(26.43 \%){ }^{14}$ We can think that the operation was decided according to the other malignancy criteria by the follow up although the FNAB result was benign. In this study 60 (3.4\%) patients were detected as Bethesda-III. However, more recent studies have shown that the incidence of the Bethesda-III category was to be high as $10-12 \% .^{15-16}$ Essentially, AUS/FLUS implies an intermediate histologic grade between the benign and malignant grades. Therefore, it is the most undecided FNAB result about the malignancy diagnosis. In our study, 13 (21.6\%) patients underwent surgery in AUS category and malignancy rate was detected as 23,07\%. In the study by Erivwo et al. ${ }^{17}$, malignancy rate was found to be $29.8 \%$ in AUS category. Ryu et al. ${ }^{18}$ reported this rate as $35.3 \%$ and Mileva et al. ${ }^{19}$ reported as $36.1 \%$. We think that the fallibility of the ratio may occur due to the different experiences and competencies of pathology and radiology specialists.

In this study, we found ten benign and only three malign histopathological results in patients with thyroidectomy in the AUS group. NLR comparison between these groups could not be made due to the low number of patients. In a study of the patients who underwent thyroidectomy with AUS and SM categories, a comparison was made between benign and malignant groups in terms of NLR and no significant difference was found. ${ }^{20}$ On the other hand, some studies have shown that the other criteria are much important than the NLR as well as the pathological results in the malignancy diagnosis and surgical decision of the AUS category. In the study of Ryu et al. ${ }^{18}$, the increase in age was found to be parallel with the increase in the risk of thyroid malignancy in the patients with Bethesda-III category by the follow-up. In the study of Remonti et al. ${ }^{21}$ it was reported that microcalcification and central vascularization provides by $96 \%$ the malignancy diagnosis in Bethesda-III category.

There are some studies in which the NLR was evaluated in the thyroid malignancy based on thyroiditis. Kocer et al. ${ }^{9}$ reported that there was no difference in NLR between papillary thyroid cancer groups with and without lymphocytic thyroiditis on the basis. Similarly, in the study of Eroglu et al. ${ }^{22}$, NLR was evaluated in nodular hyperplasia, thyroiditis, papillary ca and papillary ca with thyroiditis. No statistical difference was found between the groups in terms of NLR. Ari et al. ${ }^{23}$ found that the mean NLR was significantly higher in the thyroiditis group and non-significantly higher in the papillary cancer group than in the healthy group. However, no significant difference was found between the thyroiditis and papillary cancer groups. In our study, postoperative histopathological results revealed 3 granulomatous and 3 Hashimato thyroiditis and 7 lymphocytic thyroiditis. In the AUS group, there was only one lymphocytic thyroiditis. Unfortunately, the low number of thyroiditis was insufficient for us to compare the effect of thyroiditis on NLR in this study.

We recognize certain limitations to our study. Firstly and major limitation was the retrospective design and relatively small simple size in AUS category. Secondly, the number of patients in the groups was heterogeneous, which may have statistically negatively affected our results. Thirdly, it was limited to a certain geographical region; therefore, the results may not be generalizable. Despite these limitations, there is an advantage of this study such as there are a limited number of studies in the literature that examine the relationship between the AUS category and NLR, but this relationship is not clear yet. We hope that it can make a concept for the future studies. 


\section{Conclusions}

In conclusion, the present study showed that NLR does not differ according to Bethesda categories.

Additionally, the patients who underwent thyroidectomy also did not show any difference in NLR from those who did not. Moreover, there was no difference in NLR between benign and malignant postoperative histopathologic results. We think that it is not possible to say that NLR has a predictive role in making the decision of follow-up or surgery in the AUS category.

\section{Conflict of interest}

The authors declared that there are no potential conflicts of interest with respect to the research, authorship, and/or publication of this article.

\section{Authors' Contribution}

Study Conception: OO; Study Design: OO, HC; Supervision: OO; Materials: OO, HC, CA, MCA; Data Collection and/or Processing: OO, HC, CA, MCA; Statistical Analysis and/or Data Interpretation: CA; Literature Review: OO; Manuscript Preparation: OO; and Critical Review: $\mathrm{OO}, \mathrm{HC}, \mathrm{CA}$.

\section{References}

1. Guth S, Theune U, Aberle J, Galach A, Bamberger CM. Very high prevalence of thyroid nodules detected by high frequency $(13 \mathrm{MHz})$ ultrasound examination. Eur J Clin Invest. 2009 Aug;39(8):699-706. doi: 10.1111/j.13652362.2009.02162.x.

2. Cibas ES, Ali SZ. The 2017 Bethesda system for reporting thyroid cytopathology. Thyroid. 2017 Nov;27(11):1341-6. doi: 10.1089/thy.2017.0500.

3. Balkwill F, Mantovani A. Inflammation and cancer: back to Virchow? Lancet. 2001 Feb 17;357(9255):539-45. doi: 10.1016/S0140-6736(00)04046-0.

4. Moore MM, Chua W, Charles KA, Clarke SJ. Inflammation and cancer: causes and consequences. Clin Pharmacol Ther. 2010 Apr;87(4):504-8. doi: 10.1038/ clpt.2009.254.

5. Diakos CI, Charles KA, McMillan DC, Clarke SJ. Cancer-related inflammation and treatment effectiveness. Lancet Oncol. 2014 Oct;15(11):e493-503. doi: 10.1016/ S1470-2045(14)70263-3.

6. Walsh SR, Cook EJ, Goulder F, Justin TA, Keeling NJ. Neutrophil-lymphocyte ratio as a prognostic factor in colorectal cancer. J Surg Oncol. 2005 Sep 1;91(3):181-4. doi: $10.1002 /$ jso.20329.

7. Bhatti I, Peacock O, Lloyd G, Larvin M, Hall RI.
Preoperative hematologic markers as independent predictors of prognosis in resected pancreatic ductal adenocarcinoma: neutrophil-lymphocyte versus plateletlymphocyte ratio. Am J Surg. 2010 Aug;200(2):197-203. doi: 10.1016/j.amjsurg.2009.08.041.

8. Nakamura N, Kinami S, Fujii Y, Miura S, Fujita J, Kaida D, Tomita Y, Miyata T, Fujita H, Ueda N, Iida Y, Kosaka T. The neutrophil/lymphocyte ratio as a predictor of peritoneal metastasis during staging laparoscopy for advanced gastric cancer: a retrospective cohort analysis. World J Surg Oncol. 2019 Jun 25;17(1):108. doi: 10.1186/ s12957-019-1651-3.

9. Kocer D, Karakukcu C, Karaman H, Gokay F, Bayram F. May the neutrophil/lymphocyte ratio be a predictor in the differentiation of different thyroid disorders? Asian Pac J Cancer Prev. 2015;16(9):3875-9. doi: 10.7314/ apjcp.2015.16.9.3875.

10. Çadirci K, Yildız F, Keskin H, Bayrak M, Özmen HK, Durmaz SA, Çarlioglu A. Investigation of the neutrophil/lymphocyte and monocyte to high-density lipoprotein cholesterol ratios in differentiated thyroid cancers. J Health Sci Med. 2020;3(2):172-5. doi: 10.32322/ jhsm.689142.

11. Sit M, Aktas G, Erkol H, Yaman S, Keyif F, Savli H. Neutrophil to lymphocyte ratio is useful in differentiation of malign and benign thyroid nodules. P R Health Sci J. 2019 Mar;38(1):60-3.

12. Yaylaci S, Tosun O, Sahin O, Genc AB, Aydin E, Demiral G, Karahalil F, Olt S, Ergenc H, Varim C. Lack of variation in inflammatory hematological parameters between benign nodular goiter and papillary thyroid cancer. Asian Pac J Cancer Prev. 2016;17(4):2321-3. doi: 10.7314/apjcp.2016.17.4.2321.

13. Liu JF, Ba L, Lv H, Lv D, Du JT, Jing XM, Yang NJ, Wang SX, Li C, Li XX. Association between neutrophilto-lymphocyte ratio and differentiated thyroid cancer: a meta-analysis. Sci Rep. 2016 Dec 12;6:38551. doi: 10.1038/ srep38551.

14. Ling J, Li W, Lalwani N. Atypia of undetermined significance/follicular lesions of undetermined significance: What radiologists need to know. Neuroradiol J. 2021 Apr;34(2):70-9. doi: 10.1177/1971400920983566.

15. Garg S, Naik LP, Kothari KS, Fernandes GC, Agnihotri MA, Gokhale JC. Evaluation of thyroid nodules classified as Bethesda category III on FNAC. J Cytol. 2017 JanMar;34(1):5-9. doi: 10.4103/0970-9371.197590.

16. Sullivan PS, Hirschowitz SL, Fung PC, Apple SK. The impact of atypia/follicular lesion of undetermined significance and repeat fine-needle aspiration: 5 years before and after implementation of the Bethesda System. Cancer Cytopathol. 2014 Dec;122(12):866-72. doi: 10.1002/cncy. 21468.

17. Erivwo P, Ghosh C. Atypia of undetermined significance in thyroid fine-needle aspirations: Follow-Up and Outcome Experience in Newfoundland, Canada. Acta Cytol. 2018;62(2):85-92. doi: 10.1159/000486779.

18. Ryu YJ, Jung YS, Yoon HC, Hwang MJ, Shin SH, Cho JS, Lee JS, Kim HK, Kang HC, Lim HS, Yoon JH, Park $\mathrm{MH}$. Atypia of undetermined significance on thyroid fine needle aspiration: surgical outcome and risk factors for malignancy. Ann Surg Treat Res. 2014 Mar;86(3):109-14. doi: 10.4174/astr.2014.86.3.109.

19. Mileva M, Stoilovska B, Jovanovska A, Ugrinska A, Petrushevska G, Kostadinova-Kunovska S, Miladinova $\mathrm{D}$, Majstorov V. Thyroid cancer detection rate and 
associated risk factors in patients with thyroid nodules classified as Bethesda category III. Radiol Oncol. 2018 Sep 27;52(4):370-6. doi: 10.2478/raon-2018-0039.

20. Bayır Ö, Karagöz T, Öcal B, Çakal E, Saylam G, Korkmaz MH. Predictive role of neutrophil- lymphocyte and platelet-lymphocyte ratios in thyroid nodules with cytological diagnosis of "undetermined significance" and "suspicious for malignancy". ENT Updates. 2017;7(1):2832. doi:10.2399/jmu.2017001003.

21. Remonti LR, Kramer CK, Leitão CB, Pinto LC, Gross JL. Thyroid ultrasound features and risk of carcinoma: a systematic review and meta-analysis of observational studies. Thyroid. 2015 May;25(5):538-50. doi: 10.1089/ thy.2014.0353.
22. Eroglu AH, Karayol SS, Guvendic B, Adalid Y. Predictive value of inflammatory cell ratios in incidental thyroid papillary carcinoma. Fam Pract Palliat Care. 2019 Dec;4(3):85-8. doi: 10.22391/fppc.518251.

23. Ari A, Gunver F. Comparison of neutrophil-lymphocyte ratio and platelet-lymphocyte ratio in patients with thyroiditis and papillary tumors. J Int Med Res. 2019 May;47(5):2077-83. doi: 10.1177/0300060519838392. 